\title{
La intensidad polémica en el discurso de Cambiemos. Antagonismo y exclusión en "el tiempo del diálogo" (Argentina, diciembre 2015-octubre 2017)
}

The polemic intensity in Cambiemos' discourse. Antagonism and exclusion in "the time of dialogue" (Argentina, December 2015-October 2017)

SILVINA CALERI

Profesora en la Facultad de Ciencia Política y RRRII - UNR. Diploma de Posgrado en Ciencias Sociales (FLACSO). Licenciada en Ciencia Política (UNR) y Profesora Universitaria en Inglés (UNR). Correo electrónico: silvinacaleri@gmail.com

Resumen

Con el fin de explorar la dimensión polémica del discurso político en su variante más conflictiva, esto es, de antagonismo y exclusión originaria, el artículo examina el otro negativo en el discurso de la coalición gobernante Cambiemos, desde las perspectivas que dan cuenta del contradestinatario en la enunciación política (Verón, 1987; García Negroni, 2016) y desde los enfoques de la teoría política que se ocupan de la relación con el enemigo (Mouffe 1999; 2000) en el sentido existencial que le otorga Carl Schmitt. Puntualmente se analiza el carácter de la dicotomía nosotros/ellos y la intensidad de disputa en los discursos en actos públicos, entrevistas y declaraciones del presidente Macri y de los referentes políticos de la coalición en los

\section{Abstract}

In order to explore the polemic dimension of political discourse in its most conflictive form, i.e., that of antagonism and originary exclusion, the article examines the negative other in the discourse of the governing Cambiemos coalition, adopting the perspectives which account for the counter-addressee in political enunciation (Verón, 1987; García Negroni, 2016), and incorporating the contributions from political theory that deal with the relation between enemies (Mouffe 1999; 2000) in the existential sense developed by Carl Schmitt. Specifically, the work analyses the nature of the dichotomy us/them and the intensity of the dispute revealed in the official speeches, statements to the press and public remarks made by president Macri and other 
Perspectivas Revista de Ciencias Sociales - ISSN 2525-1112 | Año 4 No. 7 Enero-Junio 2019, pp. 129-150

primeros dos años de gobierno (2015-2017). Del análisis surge que, junto a propuestas de diálogo y consenso inclusivo, en el discurso de Cambiemos la identidad kirchnerista se instaura como exterior constitutivo en enemistad existencial con el conjunto social, por lo que resulta impugnada en su derecho a la política. Se concluye que, aun sin abandonar de manera expresa las formas institucionales democráticas, tal tratamiento del adversario deteriora el pluralismo y la democracia.

\section{Palabras clave}

Discurso político - Mauricio Macri Coalición Cambiemos Contradestinatario - Antagonismo referents of the coalition in their first two years in government (20152017). The analysis shows that, along with dialogic and fully inclusive consensus proposals, in Cambiemos' discourse the kirchnerist identity is established as the constitutive outside in existential hostility to the entire society, being thus questioned in its right to participate in politics. As a result, even without expressly departing from the democratic institutions, such behavior towards the adversary undermines pluralism and democracy.

\section{Keywords}

Political discourse - Mauricio Macri Cambiemos coalition - Counteraddressee - Existential antagonism

\section{Introducción}

Las elecciones presidenciales a fines de 2015 en la Argentina dieron comienzo a un proceso de restauración neoliberal (Varesi, 2016) cuyo espacio político se presentó como una derecha renovada, moderna y democrática. Cambiemos, fuerza política integrada por la alianza entre Propuesta Republicana (PRO), Unión Cívica Radical y Coalición Cívica ARI, encontró en Mauricio Macri un referente indiscutido. Figura proveniente de la élite económica argentina, Macri accedió a la presidencia de la Nación con un discurso de campaña que, si bien fue evasivo respecto de su plan de gobierno, exhortaba a terminar con "los enfrentamientos y divisiones" y a "trabajar codo a codo" para "sacar el país adelante". La propuesta discursiva consiguió aunar demandas disgregadas alrededor del significante vacío del cambio a la vez que trazó una frontera antagónica con el kirchnerismo (Schuttenberg, 2017). Específicamente, nuestro planteo central es que el antagonismo consolidado en torno a tal frontera no es de carácter político sino de enemistad existencial, lo cual impone una restricción sustancial a la democracia plural.

En su discurso de asunción frente a la Asamblea Legislativa, el presidente Macri fija como meta central "unir a los argentinos" y proyecta un modelo de gobierno que saque el "enfrentamiento del centro de la escena". La referencia al enfrentamiento alude al gobierno saliente del que Macri fue opositor; y si bien la expresidenta Cristina Fernández de Kirchner es la negatividad inicial en el discurso, la 
identificación del adversario también comprende un colectivo que remite a sus partidarios, esto es, a toda la identidad kirchnerista y sus aliados. Así tenemos que en el discurso del presidente y de los principales miembros de su gobierno, junto a propuestas de acuerdo racional y consenso inclusivo, se demarca un otro postulado como la negación misma de tales posibilidades, instaurándoselo como el exterior constitutivo (Mouffe, 1999) de la identidad colectiva más amplia posible, el nosotros que conforma el conjunto político-social. En otras palabras, el adversario kirchnerista en la enunciación política de Cambiemos, no se registra como el adversario privilegiado con el cual se va a pugnar por la relación gobierno/oposición, sino como una alteridad que comporta un distanciamiento irreductible, un quiebre irrecuperable, que lo excluye de la posibilidad de convivir en el juego institucional democrático. En el conjunto discursivo la presencia de esta exclusión queda disimulada como resultado de un dispositivo que articula la apelación al orden de lo evidente, con un efecto de veracidad que prescinde de constatación e invalida la réplica. No obstante, la dimensión polémica del discurso se erige sobre una dicotomía antagónica e insalvable, y el adversario deviene "enemigo público" (Schmitt, 1984).

En este trabajo proponemos revisar la modalidad de la construcción de ese adversario en el discurso de Cambiemos, en el período que va desde el inicio de su gobierno hasta las elecciones de medio término, a fin de considerar las dificultades que esta forma de construcción de la alteridad supone en el horizonte democrático. Tal revisión integra dos perspectivas: por una parte, el enfoque de la multidestinación política (Verón, 1987; García Negroni, 2016) que permite la identificación del destinatario negativo en el discurso político; y por la otra, la descripción de este último según la categoría de antagonismo como relación con el enemigo (Mouffe 1999; 2000) en el sentido existencial (Schmitt, 1984).

De modo que el propósito se encuentra acotado; no pretendemos realizar un estudio sobre el conjunto de operaciones discursivas ante los diversos adversarios políticos en las distintas coyunturas, ni tampoco evaluar cuán efectivas tales operaciones resultan. De hecho, la polarización respecto del kirchnerismo parece haber sido una de las estrategias principales del discurso en la etapa señalada. Pero no es la operación de polarización en cuanto tal, como uno entre tantos juegos discursivos, lo que nos interesa en particular. Nuestra intención es examinar la intensidad polémica con el adversario kirchnerista en la enunciación de los representantes principales de la fuerza política Cambiemos desde la posición de gobierno, y la limitación a la democracia y al pluralismo que tal enfrentamiento conlleva.

Para el análisis se tuvieron en cuenta discursos en actos públicos y oficiales, entrevistas en distintos medios y declaraciones a la prensa en general. La revisión comprende fundamentalmente la palabra del presidente Macri y la de los principales referentes políticos ${ }^{1}$ de la coalición gobernante en el período que abarca desde diciembre de 2015 hasta octubre de 2017.

\footnotetext{
${ }^{1}$ Nos centramos principalmente en aquellos miembros del gobierno que provienen del mundo de la política, distinguiéndolos de los que surgen del mundo empresario o son CEO de grandes
} 
Perspectivas Revista de Ciencias Sociales - ISSN 2525-1112 | Año 4 No. 7 Enero-Junio 2019, pp. 129-150

\section{El otro negativo y sus variantes en el relacionamiento político}

En su muy influyente y ya clásico trabajo "La palabra adversativa" Verón (1987) explica que el rasgo distintivo del discurso político respecto del resto de los discursos sociales radica en una disociación estructural, producto de un desdoblamiento en la destinación propia de la enunciación política. En dicha enunciación no sólo está presente el destinatario positivo al cual se dirige el discurso, sino además aparece el otro negativo o contradestinatario con el cual se polemiza. También para dar cuenta de la contradestinación, García Negroni (2016) precisa las modalidades del decir con las que puede incluirse al destinatario negativo en el discurso político; así encontramos al contradestinatario en posición de no-persona, por interpelación directa en 2 da persona, de manera encubierta en 3ra persona 0 indirecta por descalificación. Ambos estudios posibilitan el reconocimiento de la figura del adversario en el discurso, y en tal sentido, brindan herramientas para identificar y describir las operaciones discursivas que se establecen con fines polémicos en el enfrentamiento del enunciador político con sus oponentes.

Ahora bien, la conceptualización del otro negativo no distingue particularmente entre contendiente, adversario, antagonista, enemigo. Sin embargo, los aportes desde el campo de la teoría política demuestran la relevancia de tales nociones en las propuestas, acciones y relaciones que se construyen en torno a la polémica. En otras palabras, de acuerdo a cómo se entienda lo político y su conflictividad, variarán los modos de concebir la alteridad con derivaciones significativas en el relacionamiento político y en la vida pública.

Para comenzar, la cualidad de enemigo refiere a la oposición más extrema y nítida en el enfrentamiento político, y concierne al oponente irreductible, el otro demonizado y respecto del cual se tiene como objetivo erradicarlo (Garand, 2014: 125). Referencia obligada para la caracterización del enemigo en términos de enemigo público, son los análisis de Schmitt, quien desde una perspectiva conservadora exalta el papel de la autoridad y la decisión (1982; 1984). Efectivamente, este pensador encuentra en la contraposición amigo/enemigo el criterio para determinar lo político, y entiende que el principio de la diferenciación concierne a aquello que queda fuera de la unidad política. El enemigo supone la negación de la forma de existencia de la comunidad política, y por ello, está excluido de la misma. Así la representación plural no sólo carece de valor en sí, sino que resulta problemática para la "identidad democrática" (1982: 233). Unidad y homogeneidad son entonces nociones que tienen un lugar central en este enfoque según el cual la conflictividad política (pública y decisiva) representa el máximo grado de disociación. El poder político consiste en "saber eliminar o alejar lo extraño y desigual que amenaza la homogeneidad" (Schmitt, 1990: 13). El planteo del enemigo tal como lo concibe Schmitt se sustenta en una unidad que no admite diferencia y, en tal sentido, no es compatible con la democracia plural.

corporaciones internacionales. Sobre la composición del gabinete ministerial y de las diferentes áreas de gobierno v. Vommaro y Gené (2017). 
En contraste, los términos competidor político, contendiente, adversario aluden a formas de construcción política diferentes entre sí, pero concebidas en contextos de pluralidad y tolerancia. En verdad, el modelo del gobierno representativo ha estado desde sus orígenes en conformidad con la idea de diversidad social (Manin: 228.). La aceptación del adversario político es, por consiguiente, presupuesto de la convivencia y el pluralismo. De ahí que en la tradición del régimen liberal democrático se subraya mayormente la necesidad del debate y la argumentación, tanto en la búsqueda de acuerdos políticos para construir consenso como en la manifestación del disenso. Entre las tradiciones teóricas más preocupadas por la formación de una voluntad común que no comprometa el pluralismo están aquellas que señalan la necesidad del entendimiento mutuo no basado en ninguna concepción sustantiva del bien. Tal es el caso, del liberalismo político, perspectiva que confía en la posibilidad de un pluralismo razonable capaz de lograr un consenso totalmente inclusivo, merced a un punto de vista que se abstraiga de las contingencias del mundo social (Rawls, 1994). En similar dirección, para el enfoque de la política deliberativa existe la posibilidad de lograr acuerdos en la esfera pública a través de procesos de discusión racionales que les permiten a los que deliberan considerar todos los argumentos, su relevancia y validez y, en consecuencia, realizar las mejores elecciones conforme a parámetros de razonabilidad, sentido común, y buena disposición para el intercambio discursivo (Habermas, 1994).

También auspician la convivencia y la aceptación del oponente las teorías elitistas de la democracia. Éstas se apoyan en la representación política y el recurso procedimental para la toma de decisiones y explican que la población no elige a sus representantes de acuerdo a temas o intereses en debate, sino más bien se limita a optar entre los individuos que compiten por el liderazgo, entre aquellos que pugnan por llegar al gobierno y tener el poder de decisión (Schumpeter, 1976: 343). La democracia es vista como un sistema de libre competencia en el cual "los electores son los compradores que, con su voto, adquieren los políticos que prefieren entre los que les son propuestos por los empresarios políticos, los cuales, con la venta de sus políticas, adquieren o conservan el poder" (Pizzorno, 1985: 12). Por su parte, los ciudadanos tienen un papel pasivo y deben responder a los ideales de tolerancia y auto-control democrático para evitar la crítica en exceso al gobierno y a la dirigencia política (Nun, 2000: 68). La contienda política desde ya está garantizada por los mecanismos y arreglos institucionales destinados a establecer la competencia, y la democracia se reduce a "una cuestión de método, disociado por completo de los fines, valores e intereses que animan la lucha de los actores colectivos" (Borón, 2012: 47).

De todos modos, tanto para las teorías pluralistas como para el liberalismo elitista, la democracia en el contexto capitalista requiere que las élites logren el consenso (Alvarado-Espina, 2018: 75). Ya sea porque subrayan la necesidad de una buena disposición para la concordia, o porque encuentran en la competencia de las élites políticas una directriz organizacional propia de la lógica del mercado, en ambas perspectivas la política queda circunscripta a un campo sin enemistades 
permanentes ni cuestionamiento de las relaciones de poder, en el cual la negociación, la avenencia o la reconciliación son posibles.

Se distancian de estas visiones conciliadoras, aunque sin apartarse de la preocupación por el pluralismo, aquellos planteos que subrayan la dimensión del poder y el antagonismo en las relaciones sociales. Estos enfoques explican que la actividad política manifiesta posiciones hostiles respecto de otras opciones, aun en los regímenes democráticos y plurales. Al respecto, Walzer sostiene que la vida política no es sólo discusión, negociación y acuerdo, es también una actividad inherente y persistentemente conflictual, en tanto exhibe intereses opuestos y filiaciones ideológicas con frecuencia irreconciliables (2004: 103). Lo cierto es que, como apunta Aboy Carlés, la amenaza de resolución extrema de lo político, su hostilidad potencial, está presente en todo esfuerzo por transformarlo "en 'política' como esfera regulada que intenta delimitar un espacio de exclusión de la muerte a través de la conversión del enemigo en adversario, opositor en una discusión o simple competidor" (2001: 65).

En la misma línea, Mouffe (1999; 2014) observa que el antagonismo inherente a lo político, en realidad, no puede ser totalmente desterrado, pero sí sublimado. Para dar cuenta de ello establece una diferenciación respecto del tratamiento del opositor político que toma nota de la conflictividad de lo político y, a la vez, brinda un criterio de distinción entre un tratamiento autoritario del opositor y uno pluralista. La diferencia radica en que la relación con el enemigo comporta un antagonismo que amenaza la propia existencia, mientras que la relación con el adversario se funda en una relación de agonismo que implica lucha política entre posiciones bien diferenciadas, en conflicto. Contrariamente a lo que sucede con el enemigo, al adversario se le reconoce legítima existencia al interior del nosotros que constituye la comunidad política.

Esta perspectiva, al diferenciar el tratamiento del oponente político en función del agonismo (relación con el adversario) y del antagonismo (relación con el enemigo existencial), nos permite considerar las variantes más conflictivas en la polémica entablada con el adversario, y dilucidar si el destinatario negativo de la enunciación política admite coexistencia en el marco democrático o exige su exclusión.

A continuación examinamos la propuesta de Cambiemos respecto del relacionamiento político y la gestión de la diferencia, para luego analizar el carácter de la adversidad en su enunciación política.

\section{"El tiempo del diálogo"}

Cuando nos centramos en el discurso de llegada al gobierno del líder de Cambiemos, las fórmulas, aspiraciones y fundamentos que se invocan en el planteamiento político se asemejan en gran medida a aquellas orientaciones que remarcan la avenencia y el diálogo y que depositan la confianza en la razón para llegar a las mejores decisiones. En concreto, se invita a desagraviar a la política, purgarla de toda beligerancia y restituirla al ámbito de la neutralidad: 
1. "Como les dije en la campaña, para mí la política no es una competencia entre dirigentes para ver quién tiene el ego más grande, es el trabajo entre dirigentes modernos que trabajan en equipo para servir a los demás [...]. Quiero pedirles que nuestro lugar de encuentro sea la verdad y que podamos reconocer cuáles son nuestros problemas para que juntos encontremos las mejores soluciones. [...] Se viene un tiempo nuevo, el tiempo del diálogo, del respeto y del trabajo en equipo, tiempo de construcción con más justicia social. [...] En la pelea irracional no gana nadie, en el acuerdo ganamos todos. Para trabajar juntos no hace falta que dejemos de lado nuestras ideas y formas de ver el mundo, tenemos que ponerlas al servicio de nuestro proyecto común y lograr la construcción de un país en el que todos podamos conseguir nuestras formas de felicidad." (Presidente Macri. Discurso ante la Asamblea Legislativa. 10/12/15)

En efecto, advertimos un conjunto de pautas cercanas a las tradiciones que reivindican la democracia deliberativa y el consenso racional. La aspiración de la sociedad transparente, ordenada, sin disrupciones y en armonía consigo misma está en consonancia con las nociones de neutralidad del gobierno y la imposibilidad de recurrir a doctrinas comprensivas o cosmovisiones para definir un horizonte común. En este sentido, la verdad se postula no como basamento para la construcción de una visión sustantiva del bien a la cual referir los fines de la sociedad (lo que desde esta mirada afectaría la pluralidad de los modos de vida y la "forma de felicidad" de cada uno), sino más bien como mecanismo trasparente de sensatez y diálogo, de entendimiento recíproco, para lograr acuerdos y consensos razonables. De manera que los ciudadanos aparecen como personas morales (vale decir, con su propia concepción del bien) capaces de encontrarse en el sentido común y en principios por todos compartidos. La tarea política, por su parte, se identifica con la gestión del buen gobierno, consistente, no en confrontar proyectos alternativos, sino en saber coordinar "el equipo" para encontrar "las mejores soluciones". El mundo de lo irracional, de las pasiones y de las ideologías debe ser dejado atrás en pos de una sociedad sin enfrentamientos, reconciliada en su orientación al "tiempo nuevo".

El ideal a seguir, por consiguiente, deposita gran confianza en una retórica de la persuasión mutua como base para la resolución dialógica y racional de los diferendos. Se puede decir que estamos ante un discurso que se rehúsa a aceptar como inevitable la dimensión de conflictividad y disputa de intereses de la política y de la democracia. En su narrativa se presenta el imperativo de bajar la intensidad del conflicto político para "unir a los argentinos". En tal sentido, el consenso es concebido "como punto de partida, no como resultado de la lucha política" (Schuttenberg, 2017: 291).

Esta interpretación de la vida pública y del relacionamiento político llevaría a conjeturar que la presencia del otro negativo en el discurso va a tomar la forma de un contendiente con el cual, al menos como posibilidad remota, puede haber acercamientos o acuerdos (especialmente cuando no medien la distorsión, la sordera, la mala fe). Vemos que el adversario político es invitado a "aprender el arte 
del acuerdo"2, a "ir más allá de legítimas diferencias" 3 , a cooperar en el intercambio democrático 4 .

Tal es la manera en que se registra mayormente la relación con la dirigencia política ajena al enfrentamiento principal desplegado en el conjunto discursivo de la coalición gobernante. Pero el actor político kirchnerista, lejos de estar incluido en esas propuestas de conciliación e intercambio deliberativo, surge como una enemistad diferente, principal. Aquí la alteridad se dispone en función de una división nosotros/ellos que opera en el discurso como un dispositivo central para la determinación del propio lugar enunciativo y cancela cualquier posibilidad de diálogo, acuerdo o convivencia al deslegitimar a esa identidad de manera invalidante. En tal sentido, en el discurso de Cambiemos esta alteridad se revela en un antagonismo irreductible, de negatividad radical, y de lucha con un enemigo de carácter existencial.

Seguidamente describimos posibles configuraciones de la dicotomía nosotros/ellos con el objeto de especificar la intensidad del enfrentamiento y el carácter de la exclusión del destinatario negativo en la enunciación de Cambiemos.

\section{La dicotomía nosotros/ellos}

Comencemos señalando que el estatus del adversario en el conflicto discursivo es variable (Garand, 2016: 125) y sostiene posiciones de disociación con el enunciador de distinta intensidad, de acuerdo a cómo se conforme la relación en cada discurso particular. Por otra parte, la construcción del nosotros, de la propia identidad, se vincula en gran medida con la definición del sitio del adversario, y en tal sentido, con la oposición nosotros/ellos. Tal oposición se especifica conforme al alcance de las acusaciones y el grado de enfrentamiento que se manifiesta. Esto es, si bien la dicotomía nosotros/ellos remite siempre a una exclusión, la contraposición enunciada es de distinta índole según sea la relación que se establezca con los colectivos que conforman lo que Verón denomina "entidades del imaginario político", particularmente, los colectivos de identificación (el propio y el del adversario), las entidades que designan colectivos más amplios y numerables, y los meta-colectivos singulares, colectivos plenos que abarcan la totalidad social (1987: 18-19). Dicho de otra manera, si bien en la dicotomización de los discursos "dos posiciones antitéticas se excluyen mutuamente" (Amossy, 2016: 27), la dicotomía nosotros/ellos no entraña necesariamente una relación amigo/enemigo en términos existenciales, es decir, que excluya al adversario político del espacio simbólico colectivo. Contrariamente, puede expresar formas de disputa que implícitamente

\footnotetext{
2 Macri. Asunción presidencial. 10/12/15.

${ }^{3}$ Macri. Apertura de sesiones del Congreso de la Nación. 1/3/17.

${ }^{4}$ Claro está, en la práctica son más las veces que la dinámica de la vida política impide que el intercambio deseado se produzca. En este tipo de concepciones, como señala Lechner, si bien la decisión política representa fundamentalmente acuerdos con beneficios mutuos y no un acto de autoridad que reclama obediencias, en tanto en cuanto la agenda política atiende a la urgencia de la coyuntura que demanda decisiones inmediatas, el «decisionismo» le gana a la coordinación y cooperación (1994: 35).
} 
reconozcan que en el juego de la política los oponentes intentan derrotarse mutuamente, sin prefigurar una exclusión irreductible, sin exigir la anulación del adversario como actor político. De ello se deriva que la configuración de una forma determinada de dicotomía en lugar de otra tiene consecuencias concretas a la hora de demarcar el estatus del oponente político.

Para comenzar, la dicotomía puede tratarse de una relación en la que el adversario queda excluido del colectivo de identificación del enunciador (nuestro partido, nuestra alianza, nuestro gobierno), y situado en un lugar de reprobación, ya sea por incapacidad, insensatez o falsedad. Podríamos sintetizar esta oposición en la fórmula «nuestra fuerza política versus la fuerza política de ellos».

Pero además el enunciador político tiene la necesidad de trascender la identidad partidaria y proponer colectivos más abarcadores que amplíen los espacios de recepción (Arfuch, 1987; Verón, 1987; García Negroni, 2016). Así la oposición nosotros/ellos se constituye en función de colectivos que interpelan a destinatarios en situación de ser persuadidos por el discurso y los alejan del contradestinatario al que se desaprueba. Al incluir a amplios sectores de la ciudadanía, la oposición se resume como «nosotros y otros más versus ellos».

Para identificar otra posibilidad de la dicotomía nosotros/ellos, resultan útiles las observaciones de Sigal y Verón sobre esta relación en el discurso peronista. Puntualmente, encontramos la descripción de un clivaje que nos remite a pensar en un otro negativo formulado en función de una exclusión diferente a las expuestas en los párrafos anteriores. De acuerdo a esta perspectiva, el dispositivo peronista consiste en una oposición (antagónica) entre un nosotros que se identifica con el colectivo más amplio posible ('los argentinos') y un ellos que se encuentra expulsado de tal colectivo, carente de proyecto político propio y, por ende, despojado de toda racionalidad e identidad (2004: 77). ${ }^{5}$

Sin duda, la apelación a colectivos muy abarcadores, colectivos con una identidad completamente inclusiva y plena, enlaza con el conjunto social. En tal caso, la dicotomía nosotros/ellos plantea la separación entre por un lado, la identidad del enunciador identificado con el meta-colectivo (el país, la Nación, el pueblo), y por el otro, el adversario que queda fuera de dicho colectivo social. En esta variante discursiva la disociación se intensifica ya que el nosotros reclama la representación de la sociedad en su conjunto; este sería el caso de oposiciones tales como oligarquía/pueblo, patria/colonia, liberación/dependencia, pueblo/casta.

Nuestro argumento en este punto sostiene que recién a partir de la instauración del otro negativo fuera del meta-colectivo es que se logra realizar la identificación entre el enunciador con el colectivo pleno y se establece la relación de

\footnotetext{
${ }^{5}$ Los autores caracterizan esta monopolización del nosotros pleno como específica del discurso peronista, al cual le adjudican el "vaciamiento del campo político" y un "carácter trans-ideológico" (65-97). Sobre tales conclusiones, seguimos a Barros quien advierte que éstos no son aspectos exclusivos del discurso peronista, sino rasgos de la constitución de cualquier discurso, y explica que cada posición específica tiene "la capacidad de 'vaciar' su contenido particular y cambiar hacia una más universal representación de una nueva estructuralidad" (2002: 41).
} 
antagonismo ${ }^{6}$. En otras palabras, para la constitución de un nosotros totalmente inclusivo (ya sea nosotros el pueblo, nosotros los argentinos, nosotros el país, nosotros la nación), es necesario distinguirlo de un ellos que se enuncia excluido de la identidad colectiva más amplia, en contradicción insalvable.

La noción de exterior constitutivo que Mouffe (1999; 2000) recupera de Derrida da cuenta de esta relación. La autora explica que no hay identidad que se autoconstituya; la condición de existencia de toda identidad es la afirmación de una diferencia, su exterior constitutivo. El antagonismo es inherente a toda objetividad social, y todas las formas de consenso se basan en actos de exclusión. De ahí que la dicotomía nosotros/ellos sea central en la constitución de identidades políticas colectivas.

En esta modalidad de enfrentamiento el enunciador se posiciona junto a la comunidad por lo que la relación se resume como «todos nosotros versus ellos». El destinatario negativo no solo está excluido de identidades que remiten a posicionamientos político-partidarios (o inclusive excluido de colectivos más amplios que pueden abarcar distintas mayorías), sino que además queda en disputa antagónica con la totalidad social.

No obstante, en esta última dicotomía podemos hacer una distinción entre dos modalidades posibles, ya sea que la función polémica del discurso niegue o, por el contrario, recupere la legitimidad de la existencia del adversario como tal. Puntualmente, el adversario es reconocido como legítimo cuando el antagonismo aparece mediado por el programa político que pretende hegemonizar la resolución del conflicto social. De tal modo, la separación nosotros/ellos se postula como oposición entre propuestas políticas sustancialmente diferentes y antagónicas, por lo que la formulación de la dicotomía podría sintetizarse como «nuestro programa versus el programa de ellos». Trazada así la disyuntiva, el programa o proyecto propio alcanza a toda la sociedad y es incompatible con el programa del adversario. Pero el antagonismo es con el programa, no con el adversario, al cual se le sigue reconociendo el derecho de participar en la vida política aun cuando se trate de una voluntad de poder opuesta.

Pues bien, según se acepte o no la legitimidad del oponente político en cuanto tal, y siguiendo la diferenciación de Mouffe (2014), podemos referirnos al adversario agónico (conforme al pluralismo) o al adversario antagónico (asimilable al enemigo).

Aclaramos en este punto que nos estamos refiriendo a un antagonismo originario o existencial, al cual diferenciamos del antagonismo como enemistad política ${ }^{7}$ (a nuestro juicio más próximo a la noción de agonismo de Mouffe). Según sugerimos,

\footnotetext{
${ }^{6}$ A diferencia del análisis de Sigal y Verón según el cual la operación de identificar al enunciador y su colectivos (Perón y los peronistas) con colectivos tales como el pueblo, el país, la Nación deja al adversario fuera del marco de referencia colectivo para constituirlo en "el enemigo del pueblo, del país, de la Nación" ((2004: 71-78).

${ }^{7}$ Franzé (2017) advierte la diferencia entre la enemistad política que encontramos en Laclau y el concepto de enemistad existencial en Schmitt, pero la relativiza en lo que hace al carácter ontológico que se le atribuye a lo político. Señala que en ambas visiones lo político se define por el antagonismo, instituye lo social y constituye los sujetos; y no se deriva de ninguna secuencia objetiva o lógica. Para este argumento v. Laclau (2005: 111-112) y Schmitt (1984: 23-24).
} 
la distancia entre uno y otro reside en el modo en que se conciben la unidad política y el pluralismo. En lo que hace al antagonismo político presente en los análisis del posestructuralismo, vemos que la división hacia el interior del demos no es considerada necesariamente problemática; mientras que en la concepción de enemistad existencial en Schmitt el pluralismo ineludiblemente niega la unidad política, por lo cual la división y el antagonismo deben ser expulsados del demos.

En verdad, la posición de la democracia radicalizada no reniega de la ideología plural-democrática, sino que propone profundizar y expandir el momento democrático de la misma (Laclau y Mouffe, 1987: 199). Igualmente, en el examen del populismo como "juego inconcluso" de articulaciones diferenciales y equivalenciales, las fronteras políticas son contingentes y no derivan de convergencias impuestas a priori (Laclau, 2005: 117). El antagonismo político, que establece fronteras de exclusión para la constitución discursiva de las identidades colectivas, se plasma en el campo de lo simbólico. La conformación de una frontera hacia el interior de la comunidad política significa la lucha por la hegemonía en el espacio público, la disputa por la construcción de sentido.

El enfoque sostiene, a su vez, que el discurso populista permite la dicotomización del campo político que opone el pueblo a las élites tradicionales, "construcción por la cual los sectores subalternos reclaman con éxito la representación de un interés general olvidado o traicionado" (Errejón y Mouffe, 2015: 87). Hay un reconocimiento, entonces, de la naturaleza plural y disgregada de las sociedades contemporáneas junto con la posibilidad de inscripción de las singularidades en una precaria unidad. La realidad social se entiende como heterogénea y fluctuante; los sujetos no están constituidos de manera irrevocable, las identidades son abiertas, se configuran y reconfiguran en la disputa por el sentido del orden. (Laclau y Mouffe, 1987: 128; Mouffe, 2000: 55-56; Laclau, 2005: 150-151). De manera que lejos está esta perspectiva de imaginar la enemistad política para la declaración de hostis o enemigo interno ante la "necesidad de pacificación" intra-estatal que indica Schmitt (1984: 42). Más bien, se acerca a pensar la democracia como una institución en la que no hay posiciones a priori ni interpretaciones irreversibles, y en la cual, en palabras de Castoriadis, "todas las preguntas pueden ser planteadas" (2000: 148).

En el caso del enemigo existencial, en cambio, vemos que éste se constituye en función de una exclusión originaria al exterior de la unidad política, la cual es interpretada como una entidad dada y, por lo tanto, estable. La distinción nosotros/ellos no es resultado de una articulación hegemónica, sino del reconocimiento de fronteras ya existentes (Mouffe, 2000: 54) que suponen la homogeneidad del demos. Como el enemigo compromete la existencia propia, la coexistencia es imposible y el enemigo se vuelve enemigo público (Schmitt, 1982; 1984). En síntesis, se anula la política interna y la posibilidad de disputa al interior de la comunidad política.

En lo que sigue examinamos la intensidad del enfrentamiento en la enunciación de Cambiemos. 
Perspectivas Revista de Ciencias Sociales - ISSN 2525-1112 | Año 4 No. 7 Enero-Junio 2019, pp. 129-150

\section{El antagonismo existencial}

De las modalidades en la relación nosotros/ellos aquí propuestas, la dicotomía antagónica existencial «todos nosotros versus ellos» constituye la operación polémica central del discurso del presidente Macri y de su espacio político. Veamos el siguiente pasaje:

2. "Podemos pensar de distinta forma, pero la ley debe ser respetada. Una cosa es tener distintas visiones, ideas y propuestas, otra avasallar las instituciones con proyectos personalistas o hacer uso del poder en beneficio propio. Ahí no hay una cuestión de opiniones diversas, se trata de la transgresión de la ley. El autoritarismo no es una idea distinta, es el intento de limitar la libertad de las ideas y de las personas." (Presidente Macri. Discurso de Asunción ante la Asamblea Legislativa. 10/12/15)

Se observará que, aunque el adversario no está explicitado y la contradestinación es indirecta ${ }^{8}$, el señalamiento es inequívoco: las marcas de polifonía ${ }^{9}$ introducen enunciados adjudicados a la identidad política kirchnerista, y la fórmula "proyectos personalistas" alude polémicamente al liderazgo de Cristina Fernández de Kirchner. La toma de distancia expresa un intenso grado de conflictividad y despliega una disputa con lo inadmisible; no sólo se ubica al destinatario negativo en el terreno de lo indeseable y censurable, sino que se lo invalida absolutamente en su calidad de adversario. De modo que relación dicotómica nosotros/ellos es de antagonismo existencial.

A diferencia de las otras dicotomías descriptas, en las que subyace el supuesto de que los ciudadanos tienen la posibilidad de elegir entre alternativas posibles (líderes políticos, partidos, programas), en la dicotomía antagónica existencial el adversario político no puede ser nunca una opción. Concretamente en este caso, no puede serlo porque está identificado con las prácticas de "avasallar las instituciones", "hacer uso del poder en beneficio propio", "la transgresión a la ley", el "autoritarismo", prácticas todas que lo impugnan en su legitimidad.

De forma tácita, se le niega al otro negativo del discurso (la identidad kirchnerista) la licitud de convivir en el ámbito institucional democrático, pues lo suyo atenta contra el régimen democrático mismo. Visualizado como amenaza o menoscabo a las instituciones democráticas, y por tanto privado de legitimidad, este adversario se convierte en enemigo existencial. Ya no es contemplado como adversario político, sino en antagonismo con el orden democrático, por lo cual pierde la categoría de adversario y se conforma, respecto de tal orden, en su exterior constitutivo.

\footnotetext{
${ }^{8}$ Como acto de descalificación oculto en complejos alocucionarios (García Negroni, 2016: 41).

${ }^{9}$ La conjunción adversativa pero y la negación. Por ejemplo, el enunciado negativo ("no es una idea distinta") permite introducir en el discurso un sujeto diferente del que en realidad habla. La voz del adversario es puesta en escena atribuyéndosele a éste una enunciación que pretende justificar paradójicamente aquello que lo convierte en ilegitimo (el "autoritarismo"). Acerca del fenómeno de la negación en la teoría de la polifonía, v. Ducrot (1984: 264-270).
} 
Perspectivas Revista de Ciencias Sociales - ISSN 2525-1112 | Año 4 No. 7 Enero-Junio 2019, pp. 129-150

Así pues, ubicar al destinatario negativo en el espacio simbólico de lo inaceptable, de lo ilegítimo, fuera del marco legal declarado y reconocido como válido por la sociedad, permite al enunciador Cambiemos la constitución de un nosotros que comprende la totalidad social. $Y$ por añadidura, este discurso se arroga la representación de todos los ciudadanos, de todo el orden político, cuya anuencia no se pone en duda.

Por otro lado, el adversario antagónico no está singularizado en un actor individual, sino que remite a un colectivo genérico y difuso, "el kirchnerismo" representado como un todo. En los siguientes fragmentos podemos verificar el antagonismo en el contexto de una serie de operaciones que lo encubren.

3. "Se pueden solucionar los problemas de la gente si trabajamos en equipo, si escuchamos al otro, si nos sentamos en la misma mesa a resolver los problemas [...] Este cambio que estamos implementando y que se va a consolidar a partir de este domingo en cada una de las elecciones del país, es una propuesta de cara al futuro para dejar atrás al pasado, el populismo, la corrupción, la destrucción de las instituciones y la imposibilidad de escuchar al otro." (Ministro del Interior, Obras Públicas y Vivienda Rogelio Frigerio. Acto en el Club Regatas en Corrientes y firma de Actas para la construcción de viviendas y en respaldo para la campaña municipal. 1/6/17)

4. "Después de una década de despilfarro y corrupción, empezamos a normalizar el sector energético para que las familias, los comercios y las fábricas tengan energía cuando la necesitan." (Presidente Macri. Discurso de Apertura de Sesiones Ordinarias del Congreso. 1/3/17)

5. "Por eso hemos puesto en marcha más de 20000 kilómetros de caminos y autopistas que se construyen a precios entre el 20 y el $50 \%$ más barato. Porque nunca más las obras volverán a ser sinónimo de corrupción. Sino sinónimo de esperanza, de optimismo, de alegría." (Presidente Macri. Exposición Rural. 29/7/17).

Como señalamos, la operación de denuncia que excluye al adversario del campo político legítimo autoriza al enunciador para instaurarse como el representante del conjunto social y le otorga voz privilegiada en la relación de antagonismo nosotros/ellos. Al mismo tiempo, lo polémico está expuesto en articulación con el componente programático, del compromiso y del desempeño futuro, lo que otorga al discurso un efecto de positividad y entusiasmo y, sobre todo, de buena voluntad que disimula la hostilidad de la imputación. ${ }^{10}$

\footnotetext{
${ }^{10}$ En nuestro trabajo sobre la dimensión polémica en el discurso de Elisa Carrió, señalábamos que la disputa con el adversario antagónico estaba formulada principalmente en torno al deber ser, con predominio de enunciados descriptivos que desdibujaban en ese discurso aspectos del orden del poder hacer (Caleri y Recio, 2004). En el discurso de Cambiemos la función polémica se reitera en contrapunto con la promesa de hacer.
} 
Perspectivas Revista de Ciencias Sociales - ISSN 2525-1112 | Año 4 No. 7 Enero-Junio 2019, pp. 129-150

Además, este discurso se construye a sí mismo como fuente de verdad. Sus evaluaciones se postulan como descripciones verdaderas solo por ser enunciadas, lo cual permite ocultar la controversia y soslayar cualquier argumentación en contrario. Los sintagmas "la década de despilfarro y corrupción" o "la destrucción de las instituciones", denuncian al colectivo kirchnerista en la interpretación del pasado, tiempo en el cual queda, a la vez, confinado. El juicio es concluyente y se cierra a otras interpretaciones. Más aún, en la enumeración de rótulos acusatorios se alternan expresiones de distinto tenor y gravedad colocadas en un mismo plano. De este modo se borra el límite entre lo lícito (ser populista, tener sordera política, negarse a dialogar) y lo ilícito (ser corrupto, destruir las instituciones), lo que compone una relación de igualdad, de asociación automática entre "populismo", "corrupción”, "despilfarro", "destrucción de las instituciones", características intercambiables que sirven para dar sentido alternadamente a las reiteradas fórmulas polémicas "la pesada herencia" y "un país quebrado".

Y como la acusación es incontestable, este adversario ilegítimo no tiene resquicio para la réplica; su impugnación, al ser formulada como autoevidente y verdadera, no necesita validación. Tampoco es necesaria la exhortación a la condena pública puesto que esta última se da por sentada - a tal punto, que la inhabilitación de este otro negativo está incorporada en el programa de gobierno como propósito y promesa. Con estilos diferentes según el dirigente del que se trate, esta empresa de aspiración justa y gestión tenaz se halla presente en el conjunto discursivo de los referentes de la coalición gobernante. Por ejemplo:

6. "Voy a impulsar una ley del arrepentido para casos de corrupción. Pero ya hay herramientas que son muy similares y sería bueno que los jueces las usen en este momento." (Presidente Macri. Entrevista en A Dos Voces, Canal TN. $30 / 3 / 16)$

7. "Me decían: "Lilita es imposible luchar contra la corrupción." Y hoy, los que estaban, no solo no están, sino que están en proceso. (Diputada Elisa Carrió Conferencia por Facebook Live en campaña por la reelección de su banca." 20/6/17).

8. "Celebramos que el Poder Judicial hoy en día esté decidido a investigar los hechos de corrupción del pasado. $Y$ ojalá que eso termine en sanciones, en funcionarios corruptos presos y sobre todo que termine en que estos exfuncionarios devuelvan el dinero que le robaron a la gente." (Ministro Frigerio. Entrevista en Radio Salta. 12/6/16)

Desplazado de modo cabal e ineludible de la comunidad del orden y colocado al margen de la ley, en antagonismo con la sociedad toda, la identidad política kirchnerista deviene en el discurso de Cambiemos en una suerte de enemigo 
Perspectivas Revista de Ciencias Sociales - ISSN 2525-1112 | Año 4 No. 7 Enero-Junio 2019, pp. 129-150

público $^{11}$ hacia el interior de la unidad política. Este enemigo público enunciado, si bien no puede ser eliminado, debe quedar inhabilitado como identidad política. ${ }^{12}$ En tal sentido, el posicionamiento en esta disputa es un imperativo, debe ser claro e inequívoco, no hay margen para la neutralidad:

9. "De los corruptos se tiene que ocupar la Justicia, que tiene que ser rápida y dar respuesta a todas las denuncias que hay hoy en la Argentina acerca de la corrupción que hemos vivido en el pasado." (Presidente Macri. Acto de campaña legislativa. Posadas. 27/7/17)

10. "Si el señor De Vido" ${ }^{13}$, que es un emblema, tiene demasiados amigos en la Justicia Federal, los miembros de la Justicia Federal tienen que saber que ¡cuidado! Los argentinos queremos saber la verdad, así que más vale que nos representen. Si no, vamos a buscar otros jueces que nos representen." (Presidente Macri. Cierre del Seminario Justicia y Transparencia del Colegio Público de Abogados de la CABA. 1/6/17)

11. "Hasta hace dos años esos señores gobernaban con impunidad el país, con mucho poder, con la prepotencia de la cadena nacional, de la corrupción, de la falta de diálogo [...] Y hoy están teniendo que dar explicaciones de cosas que antes ni podía parecer posible. [...] Ahora esperemos que la Justicia avance con mayor velocidad. Tienen que avanzar. Tiene que haber una Justicia en tiempo real. Las causas pueden avanzar a pesar de los fueros que [De Vido] tenga." (Jefe de Gabinete Marcos Peña. Entrevista en A Dos Voces, Canal TN. 27/7/17)

El presidente Macri (como el portavoz justo de "los argentinos") interpela explícitamente a un colectivo particular de destinatarios ("los miembros de la justicia federal") a los que se les insta (en ocasiones se les conmina) a asumir ese enemigo público. En todos los casos, la condena a ese enemigo es un mandato ("tiene que ser rápida y dar respuesta", "más vale que nos representen", "tienen que avanzar"). El dispositivo discursivo se plantea de tal manera que si los destinatarios ("los jueces", el Poder Judicial) no se unen a la confrontación, serán en virtud de ello asociados al enemigo público y, en consecuencia, igualmente impugnados.

\footnotetext{
${ }^{11}$ Schmitt señala: "Enemigo es sólo el enemigo público, puesto que todo lo que se refiere a semejante agrupamiento, y en particular a un pueblo íntegro, deviene por ello mismo público. Enemigo es el hostis, no el inimicus en sentido amplio (...)" (1984: 25).

${ }^{12}$ Específicamente, Schmitt refiere al enemigo interno para caracterizar las formas de exclusión y de declaración de hostilidades internas al estado; y observa que a lo largo de la historia puede verificarse la colocación del hostis fuera de la comunidad de paz - de formas más severas o más benignas, manifiestas o encubiertas. Entre otros casos señala la proscripción fundada en que los miembros de determinados partidos carecen de inclinación a la paz o a acatar la ley (1984: 42-43).

13 Julio de Vido fue Ministro de Planificación Federal, Inversión Pública y Servicios de la Nación Argentina durante las presidencias de Néstor Kirchner y de Cristina Fernández de Kirchner (20032015).
} 
Perspectivas Revista de Ciencias Sociales - ISSN 2525-1112 | Año 4 No. 7 Enero-Junio 2019, pp. 129-150

En la enunciación de Cambiemos, el ser asociado al "kirchnerismo" trae consigo, cuanto menos, descrédito y degradación, pero además puede acarrear complicidad:

12. "Es una pena que los organismos de derechos humanos, que sabemos que algunos de ellos tuvieron y tienen mucha afinidad con la expresidenta y con el gobierno anterior, esto los termina desprestigiando. Una cosa es la desaparición [de Santiago Maldonado], que nos preocupa a todos, y otra cosa es el aprovechamiento político de esta situación ${ }^{14}$. Creo que eso la gente lo distingue." (Ministro de Justicia y DDHH Germán Garavano. Entrevista en Radio La Red. 29/8/2017)

13. "Lo dice él [Sergio Massa] que fue parte del kirchnerismo inclusive en altos cargos. Que diga lo que sabe de los funcionarios involucrados en hechos de corrupción; sino me parece un poco hipócrita la afirmación." (Jefe de Gabinete Marcos Peña. Entrevista en Radio Mitre 27/5/17) ${ }^{15}$

14. "[Gils Carbó ${ }^{16}$ ] no tiene autoridad moral para ejercer el cargo de Procuradora; no sólo es militante kirchnerista, sino que no ha impulsado la lucha contra el delito, ni la lucha contra la corrupción porque ha dilatado todos los procesos de investigación sobre hechos de corrupción del Gobierno anterior." (Presidente Macri. Entrevista en Radio Mitre. 15/7/17)

La denuncia es doblemente eficaz. Por un lado, coloca al denunciado en una situación defensiva tal que lo único que le resta por hacer para no resultar deslegitimado es desmarcarse y negar cualquier tipo de filiación con el otro negativo. Al mismo tiempo, ese desmarque no hará más que reforzar la imagen de rechazo al enemigo público.

\section{La dinámica de la exclusión originaria}

Llegados a este punto es necesario especificar cuál es la delimitación de este destinatario negativo quien la mayoría de las veces no es nombrado, sólo aludido en la reprobación de sus años de gobierno. En una primera instancia, se podría decir que este adversario grupal se compone de aquellos que efectivamente participaron del gobierno de Cristina Fernández de Kirchner. Tal composición define una identidad política específica de dirigentes políticos, tomados por otra parte colectiva e indiferenciadamente. Sin embargo, la estrategia polémica sugiere algo más: una

\footnotetext{
${ }^{14}$ Refiere a un supuesto uso político de la desaparición de Santiago Maldonado por parte de los organismos de derechos humanos.

${ }^{15}$ Ante la crítica de Sergio Massa (líder de la coalición electoral 1País para las elecciones legislativas de 2017) al gobierno de Cambiemos por ser "un gobierno de ricos".

${ }^{16}$ Alejandra Gils Carbó fue Procuradora General del Ministerio Público Fiscal de la República desde agosto de 2012 hasta su renuncia, luego de numerosas presiones y amenazas, en octubre de 2017. Vale aclarar que tal cargo tiene independencia y autonomía, rango constitucional y está a la altura de los miembros de la Corte Suprema.
} 
negatividad por momentos más difícil de delimitar. En relación con esta cuestión, es oportuna la caracterización que realiza Garand al observar que en el discurso polémico existen distintos tipos de blancos: individuales, colectivos o genéricos. Estos últimos no consisten en partidos o grupos constituidos, sino en categorías más generales, ya sea de individuos, posiciones ideológicas, adherencia a principios morales, etc. (2016: 131-133). Pues bien, algo de esto se revela en la construcción discursiva de Cambiemos en su disputa con el adversario kirchnerista. La descalificación que inhabilita no sólo apunta a un grupo de dirigentes específicos y numerables, sino también, de forma más general e indeterminada, a una categoría figurada globalmente. La operación cumple, entonces, un doble propósito: la invalidación de una identidad política concreta y la condena automática de cualquiera que profese cierta identificación o simpatía con dicha corriente política.

En resumidas cuentas, los diferentes actores políticos y sociales acaban subsumidos en la oposición y subordinados a su dinámica. No hay esfera autónoma que escape o que pueda ser indiferente al enfrentamiento. Ser kirchnerista reside en ser hostil hacia el colectivo social, y por eso mismo, este enemigo es enemigo de todos.

Asimismo, esta modalidad polémica, de impugnación originaria del adversario, basada en poner en duda el derecho de un adversario político a expresarse y participar en la vida democrática, aparece ocasionalmente en la controversia con otros actores sociales o políticos en la forma de acusación inhabilitante:

15. "[...] la mafia de los juicios laborales, eso es algo que hay que enfrentar y terminar porque destruye la generación de empleo futuro. Este grupo de estudios laboralistas, que por suerte son una minoría, con un grupo de jueces minoritarios laboralistas conducidos por Recalde ${ }^{17}$, le ha hecho mucho daño a la Argentina, porque sabemos que cuando ellos convencen a un pibe, a un trabajador de una pyme, de que tiene que hacer ese juicio indebido, y se lo hacen ganar porque tienen armadita la cosa para llevarse la mayor parte del juicio ellos, dejan a siete, ocho, diez o doce trabajadores en la calle porque la pyme cierra, y dejan a un montón más de gente sin poder acceder a un trabajo porque aquel que tiene que tomar la decisión tiene miedo a que su esfuerzo se le vaya en uno de estos comportamientos mafiosos." (Presidente Macri. Acto de Jura Ministerial. Casa Rosada. 12/6/17) ${ }^{18}$

\footnotetext{
${ }^{17}$ Refiere al dirigente kirchnerista Diputado Héctor Recalde, Jefe de Bloque (de noviembre/2015 a diciembre/201/) del Frente para la Victoria, principal fuerza opositora al gobierno de Cambiemos en la Cámara de Diputados.

${ }^{18}$ Otro ejemplo: "Hay búsquedas por distintos lugares sin la colaboración de esta organización que se declara con lineamientos bastante poco democráticos y bastante violentos." (Presidente Macri. Entrevista en Radio La Red. 11/8/17). En referencia a la comunidad mapuche Pu Lof de Cushamen, en torno a la desaparición de Santiago Maldonado en el contexto de la represión llevada a cabo por la Gendarmería Nacional ante una protesta realizada por dicha comunidad en la ruta 40 en la provincia de Chubut.
} 
Esta estrategia discursiva restringe la discusión política y limita el horizonte democrático. Al considerar al oponente fuera de la racionalidad social y en enemistad con el orden, el enunciador del discurso clausura la posibilidad de disputa legítima con el adversario político y prescinde de la necesidad de fundamento o justificación - eludiendo de tal forma prácticas primordiales de la controversia política en contextos plurales.

En principio no es de esperar que una fuerza política descripta como "derecha moderna", cuya retórica hace una valoración de la política como promotora del acuerdo y la conciliación, contenga una intensidad de enfrentamiento que comprenda el grado de mayor exclusión en la relación nosotros/ellos. Lo cierto es que en concepciones que perciben la política como la virtud del buen administrar, la negociación exitosa y el logro de acuerdos, no tiene mucha cabida el despliegue de modalidades abiertamente conflictuales. La pugna entre líderes políticos suele describirse como una contienda sobre el candidato que ofrece mejor gestión. A lo sumo, en circunstancias de mayor intensidad polémica cabe prever cierta discordia significativa en torno a programas de gobierno, o formas vehementes de disputa en las que el destinatario negativo es acusado o bien de administrar mal, ser inoperante, incapaz, o bien de ser insensato, irresponsable, mentiroso.

Al fin y al cabo, el descrédito del otro es uno de los procedimientos constitutivos de la polémica pública, en la que no solamente se argumenta por el logos sino contra el ethos del adversario (Amossy, 2016: 28). De todas maneras, las desavenencias no impiden que en algún momento los contrincantes estén dispuestos a entablar diálogos y realizar acuerdos. Por lo cual pareciera ser que esas descalificaciones no crean, necesariamente, quiebres irremediables entre los actores políticos. En realidad, en el lenguaje político tanto las acusaciones de mentira como las de error son usuales, y en cierto sentido, sobreentendidas. Sigal y Verón explican que el enunciador político debe “'trabajar' la pretensión de verdad de los discursos adversarios para mostrar, precisamente, que sólo se trata de una pretensión"; debe mostrar que tales discursos mienten o se equivocan (2004: 246).

No obstante, con el adversario kirchnerista el discurso de Cambiemos no deja margen para "aprender el arte del acuerdo" ni para suavizar peleas en pos de la convivencia democrática. Muy por el contrario, con aquel al que se denuncia por violentar las instituciones democráticas o violar la ley, poca puede ser la tolerancia. Y si bien el enfrentamiento no se formula como lucha ajena a los procedimientos previstos en el sistema político para la competencia política, la adversidad así planteada, cuando menos, complica la posibilidad de convivencia con el adversario. En este discurso no hay cabida para el reconocimiento mutuo de actores que necesitan interactuar en el marco referencial compartido del régimen liberal democrático.

\section{A modo de cierre}

Hasta aquí hemos tratado de describir al adversario en la enunciación de la coalición gobernante. En tal dirección apuntamos que, en el contexto de una 
propuesta que expresa invitar al acuerdo y a la convivencia, el discurso de Cambiemos menoscaba significativamente la tolerancia política y el pluralismo. Tal discurso traza en la dicotomía nosotros/ellos una frontera originaria que promueve la inhabilitación efectiva de una identidad política. El kirchnerista se configura en un antagonismo existencial ya que, asociado con la ilegalidad, queda excluido del colectivo social más amplio posible. Es así que, mediante una implícita declaración de hostilidad radical, toda otra instancia social o política resulta deslegitimada si se asocia con este enemigo público.

Ciertamente, esta modalidad de disputa con el adversario kirchnerista también había estado presente en la campaña presidencial de Cambiemos, e inclusive, en los años previos, en el discurso de los partidos que confluyeron posteriormente en dicha coalición. Sin embargo, el alcance de una intervención polémica no es independiente del contexto pragmático de interlocución, es decir, de las relaciones de fuerza entre los enunciadores (Garand, 2016). Por tal razón, la dimensión de enfrentamiento con un adversario irreductible adquiere en el discurso analizado una magnitud diferente dado que se formula desde la posición de autoridad institucional, con las implicancias simbólicas y perlocutivas que tal situación habilita - posición que además se muestra fortalecida por un amplio acompañamiento discursivo de los medios de comunicación, cuya concentración el gobierno de Cambiemos ha ayudado a acrecentar ${ }^{19}$.

Vimos, además, que esta modalidad de construcción del adversario en función de la exclusión de toda una identidad política establecida como inadmisible e ilegítima, entraña una forma de tratar la alteridad que puede referir de igual manera a cualquier actor, oponente o grupo político dispuesto por el enunciador. De hecho, el discurso recurre a formas enunciativas de proscripción o de expulsión de la comunidad del orden, que pueden aplicarse indistintamente al colectivo que se elija como negatividad, dependiendo de la contingencia política. No tiene un contenido explícito; no se alega una definición acabada como razón explicativa que lo distinga (su programa, su modelo económico, su posición política o concepción de la sociedad). Lo que define al enemigo es la enunciación misma, en el acto de acusar, que coloca al adversario de ocasión (designado como corrupto, mafioso, autoritario, transgresor de la ley, violento) en antagonismo con el conjunto social. En definitiva el enunciador tiene la potestad de determinar el enemigo público.

Como observamos, resulta paradójico que un planteamiento político que anuncia "un tiempo de diálogo y respeto" en "un país unido en la diversidad" establezca la polémica con la alteridad en términos de absoluta exclusión del adversario. Es cierto que la vida política democrática no puede evadir las pugnas derivadas de propuestas entre las que no hay necesariamente gran posibilidad de conciliación: voluntades de poder opuestas, fronteras con trazados divergentes, horizontes de sentido incompatibles. $Y$ desde luego, el triunfo (aunque transitorio) de una de esas voluntades en conflicto, conlleva la derrota de la otra. Así y todo, la democracia plural demanda como punto de partida que la premisa en el intercambio discursivo entre los adversarios políticos sea la tolerancia y el reconocimiento del derecho a

\footnotetext{
${ }^{19}$ Para un registro de la política de medios de comunicación del Presidente Macri, v. Álvarez (2016).
} 
Perspectivas Revista de Ciencias Sociales - ISSN 2525-1112 | Año 4 No. 7 Enero-Junio 2019, pp. 129-150

participar en la vida pública. En tal sentido, si la dimensión polémica del discurso político no puede salvar una instancia de aceptación de la legitimidad del adversario como tal, se dificulta superlativamente el pluralismo.

En suma, el discurso de Cambiemos establece un antagonismo irreductible, concreto y sin ninguna mediación; señala al adversario kirchnerista como aquel que atenta contra la supervivencia de las instituciones y la legalidad, por lo tanto no le reconoce ni admite cauce institucional a su expresión y existencia. Sin duda, aun cuando no se ponen en cuestión de manera expresa las formas institucionales básicas de la democracia, tal tratamiento del adversario acarrea un deterioro importante de la vida política democrática. Asimismo, en esta manera de enunciar la polémica, la acusación remite siempre a la exclusión como forma de argumentación polémica de cualquier adversario que sea elegido y singularizado como contrario al orden social; sin contenido específico para delimitar al enemigo, cualquiera corre el riesgo de serlo. Como resultado, lo que en principio se presenta como una propuesta de conciliación y consenso amplio, termina configurando un escenario de proscripción.

Recibido: 31/03/2019

Aceptado: 08/06/2019

\section{Referencias bibliográficas}

Aboy Carlés, G. (2001). Las dos fronteras de la democracia argentina: la reformulación de las identidades políticas de Alfonsín a Menem. Rosario: Homo Sapiens.

Alvarado-Espina, E. (2018). Una aproximación crítico-contextual al declive de la democracia en la era neoliberal. Revista Española de Ciencia Política, 0(47), 6991. Doi: http://dx.doi.org/10.21308/recp.47.03

Álvarez, R. N. (2016). Concentración y restauración. La política de medios de comunicación del Presidente Macri. $V$ Jornadas de Teoría del Estado. Cátedra de Teoría del Estado a cargo de la Dra. Beatriz Rajland. Facultad de Derecho. UBA. Buenos Aires. Recuperado de: https://www.aacademica.org/v.jornadas.de.teoria.del.estado/18

Amossy, R. (2016) Por una retórica del dissensus: las funciones de la polémica. En A. S. Montero (Comp.), El análisis del discurso polémico: disputas, querellas y controversias (pp. 25-35). Buenos Aires: Prometeo.

Arfuch, L. (1987). Dos variantes del juego de la política en el discurso electoral de 1983. En AAVV El discurso político. Lenguajes y acontecimientos (pp. 27-52). Buenos Aires: Hachette.

Barros, S. (2002). Orden, democracia y estabilidad. Discurso y política en la Argentina entre 1976 y 1991. Córdoba: Alción. 
Perspectivas Revista de Ciencias Sociales - ISSN 2525-1112 | Año 4 No. 7 Enero-Junio 2019, pp. 129-150

Borón, A. (2012). La sociedad civil después del diluvio neoliberal. En E. Sader y P. Gentili, (comp.) La trama del neoliberalismo: mercado, crisis y exclusión social (pp. 43-87). Buenos Aires: Eudeba.

Caleri, S. y Recio, M. (2004). La dimensión polémica en el discurso de campaña presidencial de Elisa Carrió. La trama de la comunicación. Anuario del Departamento de Ciencias de la Comunicación, 9, 29-40.

Castoriadis, C. (2000). Ciudadanos sin brújula. México: Ediciones Coyoacán.

Ducrot, O. (1984). El decir y lo dicho. Buenos Aire: Hachette.

Errejón, I. y Mouffe, C. (2015). Construir pueblo: hegemonía y radicalización de la democracia. Barcelona: Icaria.

Franzé, J. (2017). La trayectoria del discurso de Podemos: del antagonismo al agonismo. Revista Española de Ciencia Política, 0(44), 219-246. Doi: http://dx.doi.org/10.21308/recp.44.09

Garand, D. (2016). La función del ethos en la formación del discurso conflictivo. En A. S. Montero (Comp.), El análisis del discurso polémico: disputas, querellas y controversias (pp. 123-135). Buenos Aires: Prometeo.

García Negroni, M. M. (2016). Discurso político, contradestinación indirecta y puntos de vista evidenciales. La multidestinación en el discurso político revisitada. Revista Latinoamericana de Estudios del Discurso, 16(1), 37-59. Consultado de https://raled.comunidadaled.org/index.php/raled/article/view/44/46

Habermas, J. (1994). Tres modelos de democracia. Sobre el concepto de una política deliberativa. Ágora. Cuaderno de Estudios Políticos, 1, 41-50.

Laclau, E. (2005). La razón populista. Buenos Aires: FCE.

Laclau, E y Mouffe, C. (1987). Hegemonía y estrategia socialista. Madrid: Siglo XXI.

Lechner, N. (marzo-abril 1994). Los nuevos perfiles de la política. Un bosquejo. En Nueva Sociedad, núm. 130, 32-43.

Manin, B. (2006) Los principios del gobierno representativo. Madrid: Alianza, (primera edición 1998/primera reimpresión 2006).

Mouffe, C. (1999). El retorno de lo político. Barcelona: Paidós.

Mouffe, C. (2000). The Democratic Paradox. London: Verso.

Mouffe, C. (2014). Agonística: Pensar el mundo agonísticamente. Buenos Aires: FCE.

Nun, J. (2000). Democracia: gobierno del pueblo o gobierno de los políticos? Buenos Aires: Fondo de Cultura Económica.

Pizzorno, A. (1985) Sobre la racionalidad de la opción democrática. En AAVV Los límites de la democracia (Volumen II) (pp. 9-41). Buenos Aires: CLACSO.

Rawls, J. (1994). Ideas fundamentales del liberalismo político. Ágora. Cuaderno de Estudios Políticos, 1, 5-37.

Schmitt, C. (1982). Teoría de la Constitución. Madrid: Alianza Editorial.

Schmitt, C. (1984). El concepto de lo político. Buenos Aires: Folios. 
Perspectivas Revista de Ciencias Sociales - ISSN 2525-1112 | Año 4 No. 7 Enero-Junio 2019, pp. 129-150

Schmitt, C. (1990. Sobre el parlamentarismo. Trads. T. Nelsson y R. Grueso. Madrid: Tecnos.

Schumpeter, J. (1984). Capitalismo, socialismo y democracia. Barcelona: Ediciones Folio.

Schuttenberg, M. (2017). La política de la despolitización. Un análisis de la construcción del relato PRO. Desafíos, 29(2), 277-311. Doi: http://dx.doi.org/10.12804/revistas.urosario.edu.co/desafios/a.5259

Sigal, S. y Verón, S. (2004). Perón o muerte: los fundamentos discursivos del fenómeno peronista. Buenos Aires: Eudeba.

Verón, E. (1987). La palabra adversativa. En AAVV. El discurso político. Lenguajes y acontecimientos (pp. 11-26). Buenos Aires: Hachette.

Varesi, G. (2016). Tiempos de restauración. Balance y caracterización del gobierno de Macri en sus primeros meses. Realidad económica, 302, 6-34. Recuperado de: http://www.iade.org.ar/system/files/articulos/varesi.pdf

Vommaro, G. y Gené, M. (2017). Argentina: el año de Cambiemos. Revista de ciencia política (Santiago), 37(2), 231-254. Doi: http://dx.doi.org/10.4067/s0718090x2017000200231

Walzer, M. (2004). Politics and Passion. Toward a More Egalitarian Liberalism. New Haven: Yale University Press. 